\title{
Perceived Accessibility, Satisfaction with Daily Travel, and Life Satisfaction among the Elderly
}

\author{
Katrin Lättman ${ }^{1}\left(\mathbb{D}\right.$, Lars E. Olsson ${ }^{1}\left(\mathbb{D}\right.$, Margareta Friman ${ }^{1, *} \mathbb{C}$ and Satoshi Fujii ${ }^{2}$ \\ 1 CTF Service Research Center, and Department of Social and Psychological Studies, Karlstad University, \\ SE-65188 Karlstad, Sweden; katrin.lattman@kau.se (K.L.); lars.e.olsson@kau.se (L.E.O.) \\ 2 Kyoto University, Katsura, Nishikyo-ku, Kyoto 615-8540, Japan; fujii@trans.kuciv.kyoto-u.ac.jp \\ * Correspondence: margareta.friman@kau.se; Tel.: +46-73-460-6554
}

Received: 26 October 2019; Accepted: 13 November 2019; Published: 14 November 2019

\begin{abstract}
People are living longer than they did previously, and the proportion of older people is increasing worldwide. This rapid development will have implications for the transport system, in general, and for travel behavior and accessibility to daily activities, in particular. In recent years, both research and politics have drawn the attention of the public to issues affecting the opportunities of the elderly to participate in everyday life. The debate has so far mostly focused on health issues, with limited work having been done on the ability of the elderly to live the lives they want to considering how they travel. With this view, a theoretical model, grounded in a model of travel and subjective wellbeing was developed to explore the role of perceived accessibility in satisfaction with travel and life satisfaction. Empirical data were collected from a sample of 2422 respondents (aged 60-92) from five cities in Northern Europe (Stockholm, Helsinki, Oslo, Copenhagen, Bergen) and analyzed using partial least square structural equation modeling (PLS-SEM). The findings confirmed the link between perceived accessibility, travel satisfaction, and life satisfaction. The findings also showed the role of sociodemographic and travel attributes in perceived accessibility and satisfaction with travel, as well as the moderating effects of different age groups. We conclude that this moderating role played by age indicates that we should not always treat the elderly as a homogenous group in research and transport planning.
\end{abstract}

Keywords: elderly; daily travel; perceived accessibility; life satisfaction; PLS-SEM; satisfaction with travel

\section{Introduction}

Today, people are living longer than they did previously, and the proportion of older people is increasing worldwide. In 1950, 384 million people were over the age of 60 , corresponding to $8.6 \%$ of the population (according to [1]). This figure has since risen to nearly 900 million people (12\%). By 2050 , older people are expected to account for $22 \%$ of the world's population. This rapid growth will have implications for the transport system, in general, and for travel behavior and accessibility to daily activities, in particular.

This study focuses on the elderly (65 or older) and their general life satisfaction. The main question is whether the perceived opportunities of the elderly to live the lives they want are related to their travel satisfaction and general life satisfaction. During recent years, both research and politics have drawn public attention to issues affecting opportunities of the elderly to participate in everyday life. The debate has so far mostly focused on health issues, with limited work having been done on the ability of the elderly to live the lives they want to considering how they travel, which may include how easy it is to do daily activities, whether or not it is possible for them to do all their preferred activities, and whether or not access to preferred activities is satisfying, taking travel mode use into account. In 
this study, we relate these issues (termed perceived accessibility) to general life satisfaction in order to better understand the links between perceived accessibility, satisfaction with daily travel, and life satisfaction among the elderly.

People are getting older but also healthier; thus, definitions of "older" or "elderly needs" are not as homogeneous as they were 100 years ago. Given this, understanding and paying attention to different living circumstances of the elderly, their perceived opportunities to live the lives they want to, and their life satisfaction are necessary in transport planning and in the development of transport services suited to the elderly with different needs and preferences. We argue that a confirmed relationship between perceived accessibility in daily travel, satisfaction with travel, and life satisfaction justifies measures aimed at supporting older people to live satisfactory lives, regardless of how they travel.

In Western society the opportunity or willingness to be employed generally decreases after 64, with work no longer being a daily activity for many old people. Instead, the freed-up working time can be used for a variety of activities, such as shopping, training, religious activities, health/self-care, and social activities with friends and relatives. Some researchers claim that we live in a "hypermobile" society that requires a high degree of mobility in order to be able to take part in family/social activities, service, and business [2]. Accessibility and mobility provide opportunities for social interaction [3], which in turn helps counteracting loneliness, isolation, and exclusion by promoting meaningfulness in life and a sense of inclusion (e.g., [4,5]). Previous research on adults shows that participation in daily activities is one of the most important factors for people's life satisfaction [6]. However, knowledge of the perceived ability of the elderly to participate in their preferred activities remains limited. Furthermore, among the elderly, there is also a knowledge gap concerning the relationship between perceived accessibility, travel satisfaction, and general life satisfaction.

By analyzing data from a European public transport barometer (BEST-Benchmarking in European Service of Public Transport), we have studied the daily travel of the elderly of five different Northern European cities, as well as the relationship between perceived accessibility, satisfaction with travel, and life satisfaction. This research contributes to existing knowledge in several ways. In exploring the links between perceptions of accessibility, satisfaction with travel, and general life satisfaction, we can expect to gain increased insight into the importance of daily travel among elderly travelers. By dividing the elderly into age groups, we also expect to gain increased insight into the importance of these concepts to people undergoing different stages of life, something which may be useful in identifying priority areas when planning an inclusive transport system that promotes wellbeing.

The remainder of the paper is structured as follows: In the second section, the daily travel of the elderly is discussed, highlighting differences in travel behavior during different age stages. This is followed by a section on the theoretical framework. In the fourth section, the data collection and methodology are described. The final section contains the discussion and some recommendations for future work.

\subsection{Daily Travel}

Most studies focusing on the elderly and their daily travel have been carried out in the US [7]. In the US, as in other western countries, car use, number of trips, and the proportion of driver's license holders among older people have all increased [8]. The proportion of women with driver's licenses is less than that of men, although the number of women with driving licenses is increasing [9]. The elderly have been identified as a heterogeneous group, with different mobility and travel characteristics [10,11]. Nevertheless, knowledge of the similarities and differences in travel behavior between different segments of the elderly is lacking. Researchers have argued that the "new older generation", who are today in their 60s, are likely to adopt different travel patterns than their parents [10].

The elderly in western society are car drivers; however, due to increasing age and reduced abilities, their willingness to drive and the number of car trips is tending to decrease [12]. A trend is visible in the increasing age at which people decide to reduce their car driving. Cui, Loo, and Lin [13] present a comprehensive review of previous studies (during the 2000s) around the world (e.g., Denmark, the 
Netherlands, Canada, Australia, the UK, and the US), which shows how the number of trips and their length decrease with increasing age (often with a significant decrease after 75). The dominant mode of transport among the elderly is the car, which accounts for $84 \%-91 \%$ of all trips. However, there are variations within the group (defined in the vast majority of international studies as over 65) where the car dominates in the 75-84 bracket and primarily among men. As far as type of travel is concerned, it is the social journeys that stand out. Surprisingly, perhaps, the distances of these trips do not decrease significantly with increased age. A unique study conducted in Denver [14] analyzed the travel habits of the elderly in 2009-2010. The findings showed that "shopping trips" and "general errands" increase with age, while work-related trips fall rapidly in relation to the retirement age. Interestingly, social activities (i.e., "visiting friends/relatives" and "civic/religious") are a less common reason to travel in the oldest age group (85+).

People born after the Second World War (during the so-called "baby boom" between 1946 and 1965) are more car dependent, traveling more and further than previous generations. Cui, Loo, and Lin [13] conclude that the car is likely to continue to be the dominant mode of transport for older people. The car dependency of the elderly will further increase as these post-war children become older. As firmly pointed out by Hensher [15], "The important role that a current driver's license plays cannot be overlooked in the preservation of mobility and accessibility, ... ". Giuliano et al. [16] acknowledged that the elderly are less inclined to use public transport than other age brackets. Currie and Delbosc [17] discuss the role of public transport among the elderly and conclude that neighborhood density and mixed use residential and commercial opportunities are influential factors. Low public transport use has also been explained by functional limitations $[18,19]$. Non-motorized travel among the elderly is limited for the same reasons (e.g., [20]). A very low cycling share (6\%) is noted in North America, where older adults rarely cycle [21], while the situation is slightly more positive in Europe. For example, in the Netherlands, $25 \%$ of older adults' trips are by bicycle [22]. Böcker et al. [23] found that elderly women were more likely to walk and cycle than elderly men.

In summary, older people prefer to drive; the trend here is that they are continuing to do so at ever-increasing ages. Public transport is not an option for the vast majority of old people, slightly more old people choose to go by active modes (walking and bicycling). How perceived accessibility affects older people's travel satisfaction, and possibly their life satisfaction, is discussed in the following section, which focuses on the theoretical framework for this study.

\subsection{Theoretical Framework}

Satisfaction with daily travel refers to the subjective evaluation of travel, which is affected by both cognitive evaluations (e.g., the evaluation of perceived and physical quality aspects) and affective evaluation dimensions (e.g., emotions triggered by travel) [24]. In theory, travel satisfaction is related to people's subjective wellbeing, which includes an evaluation of life as a whole (e.g., general life satisfaction [25], see also [26]). For the elderly, this link is supported by a recent thematic synthesis of qualitative research on older people (60+) conducted in the UK between 1998 and 2017 [27]. This synthesis of 12 studies showed that travel indeed contributes to old people's wellbeing. It has also been shown that access to local facilities and services, including transport, and engaging in hobbies and leisure activities, as well as keeping up with social activities and retaining a role in society, are all closely linked to old people's wellbeing [9,28-30]. The perceived possibilities of accessing activities that are of importance to everyday life has not, however, been clarified thus far in any theoretical frameworks regarding travel and life satisfaction. Perceived accessibility is defined as perceived possibilities of accessing activities that are of importance to everyday life, or in terms of "how easy it is to live a satisfactory life considering how people travel" [31].

When it comes to empirical research on accessibility and life satisfaction of the elderly, there are very few studies focusing on the perceived possibilities of participating in or reaching important activities. Banister and Bowling [32], as well as Nordbakke and Schwanen [33], found that transport opportunities facilitating participation in social activities contribute to the quality of life of the elderly. 
Nordbakke and Schwanen further conclude, in another study [34], that the consequences of low-quality high-cost travel, or unmet mobility needs, were decreased life satisfaction of the older elderly. Enam et al. [35] discuss how the relationship between life satisfaction and activity participation may be twofold, and that the dimensions may be constantly influencing each other. A study of public transport shows that a lack of possibilities of using public transport for daily travel (due to health issues or service supply) negatively affects "the capability of elderly to carry out everyday activities of value" [36]. A study of bus travelers showed that the elderly (around the age of 68), and people in their thirties, experienced significantly lower levels of perceived accessibility when traveling by bus than did other age groups [31]. Perceived accessibility, in the study referred to, was found to be influenced by frequency of travel, quality, and feeling safe. A study by van der Vlugt, Curl, and Wittowsky [37], of perceived accessibility in Nottingham, UK, found that perceptions of accessibility decreased with age. In the study, participants rated different aspects of their daily accessibility (ease of getting to places, range of local facilities, and accessibility to necessary activities). In contrast to age, which was negatively associated with accessibility, a positive attitude toward public transport was found to be associated with higher perceived accessibility. Moreover, when investigating perceptions of walking accessibility of the elderly and families, in another case in Germany, van der Vlugt et al. [37] found that sociodemographic factors had less explanatory value regarding perceived accessibility than did attitudes. Of the sociodemographic factors, only income and disability had any effect (i.e., not age, gender, migration, car use, or education), while atmosphere, satisfaction with the availability of destinations, and different barriers were all linked to perceived accessibility.

This study contributes to previous research by clarifying the role of perceived accessibility in travel satisfaction and general life satisfaction. The model of Ettema et al. [25], of travel and subjective wellbeing, is a valuable theoretical basis that essentially postulates that satisfaction with travel influences-either positively or negatively-people's life satisfaction. However, previous research on travel and old people indicates that the ability of the elderly to live the lives they want to considering how they travel (i.e., perceived accessibility) should also be taken into account [32,33]. Thus, a link between perceived accessibility and general life satisfaction was included in the theoretical model (Figure 1). We additionally hypothesize that perceived accessibility influences travel satisfaction in that a higher degree of perceived accessibility (ease of travel, possibilities to travel, and access to preferred activities) increases satisfaction with travel while a lower degree of perceived accessibility decreases satisfaction with travel. Thus, different levels of perceived accessibility are assumed to be of significance to both travel satisfaction and general life satisfaction (see the theoretical model in Figure 1). In their review, Cui et al. [13] show how travel behavior varies during old age, which justifies the hypothesis that age group moderates the relationships between (I) perceived accessibility and satisfaction with travel, (II) satisfaction with travel and life satisfaction, and (III) perceived accessibility and life satisfaction.

To the model, we also add travel attributes (mode use) as these have been indicated to vary in old age. However, very limited research has thus far gone into the role of sociodemographic attributes and travel attributes in perceived accessibility and satisfaction with travel among the elderly, with the findings so far not giving any conclusive answers. Thus, we do not assume that there exists a relationship, adding instead potential paths (indicated by dotted arrows in the theoretical model in Figure 1) between the sociodemographic (gender) and travel attributes (frequency of mode use). 


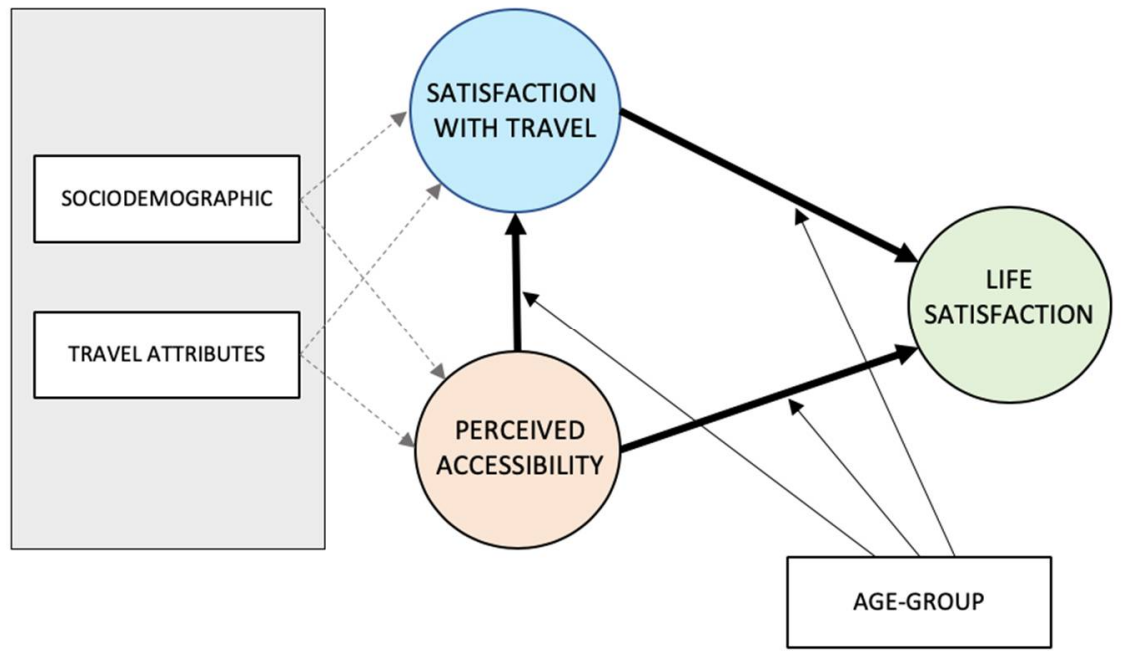

Figure 1. Theoretical model.

\subsection{The Present Study}

The aim of the present study is to better understand the links between perceived accessibility, satisfaction with daily travel, and life satisfaction by taking the diversity of older people into account. As a basis for our analyses, we therefore divide the sample into five different age groups (see Table 1), i.e., pre-retirement, early retirement, young old, old, and old with high longevity.

Table 1. Five age groups in the older population.

\begin{tabular}{ccc}
\hline Age Groups & Year of Birth & Age in 2019 \\
\hline Pre-retirement & $1958-1954$ & $60-64$ \\
Early retirement & $1953-1949$ & $65-69$ \\
Young old & $1948-1944$ & $70-74$ \\
Old & $1943-1939$ & $75-79$ \\
Old with high longevity & $1938-$ & $80-$ \\
\hline
\end{tabular}

The Results section starts with a report on travel mode use among the five age groups. We then investigate and report on the relationships outlined in the theoretical model (Figure 1), combined with multi-group comparisons, in order to detect any differences between the five different segments of elderly people.

\section{Method}

\subsection{Participants}

In total, 2422 respondents (aged 60-92) from five cities in Northern Europe (Stockholm, Helsinki, Oslo, Copenhagen, Bergen) completed self-report questionnaires (online or by phone). Sample descriptives are specified in Table 2, broken down by age group. As can be seen, the distribution between men and women was generally even, with slightly more women in the oldest age group. As expected, the employment status shift substantially from pre-retirement to retirement, and from retirement to older age groups. 
Table 2. Sample descriptives broken down by age group.

\begin{tabular}{cccccc}
\hline & \multicolumn{5}{c}{ Age Group } \\
\cline { 2 - 6 } Descriptive & Pre-Retirement & $\begin{array}{c}\text { Early } \\
\text { Retirement }\end{array}$ & $\begin{array}{c}\text { Young } \\
\text { Old }\end{array}$ & Old & $\begin{array}{c}\text { Old with High } \\
\text { Longevity }\end{array}$ \\
\hline Age & $(60-64)$ & $(65-69)$ & $(70-74)$ & $(75-79)$ & $(80-)$ \\
Number of participants $(N)$ & 675 & 536 & 587 & 318 & 306 \\
Women (\%) & 44.9 & 52.1 & 47.4 & 51.6 & 56.9 \\
Employment status (\%) & & & & & - \\
Working full time & 53.0 & 11.0 & 1.7 & 0.3 & 2.6 \\
Working part time & 10.0 & 5.4 & 3.1 & 0.9 & - \\
Retired & 30.5 & 82.3 & 94.0 & 98.0 & - \\
Other not specified & 6.5 & 1.3 & 1.2 & 0.6 & - \\
\hline
\end{tabular}

\subsection{Procedure and Measures}

The study is based on European public transport barometer data collected in 2018. Data collection was performed by a market research company, being carried out monthly using web surveys in combination with structured telephone interviews. The market research company (Norstat) complies with international quality standards (ISO 26362 and ISO 9001). Respondents are actively recruited, and the process is constantly monitored. The sociodemographic structure of the sample is compared to the general population to ensure representativeness. Personal invitations were sent out, including information about anonymity, volunteerism, and the right to drop out at any time. On completion of the survey, several types of rewards were made available, e.g., lottery tickets, cinema tickets, or charity donations.

In the questionnaire, the respondents were asked about sociodemographic factors (e.g., age, gender, and employment status) as well as to what extent they used six different travel modes (e.g., car as a driver, car as a passenger, public transport, bike, walking, and other), on a five-point Likert scale (ranging from $1=$ never to $5=$ daily).

Perceived accessibility was measured using the perceived accessibility scale (PAC) [31,38]. The respondents were asked about their perceived accessibility of daily travel by means of rating four statements (Table 3), on a seven-point Likert scale (ranging from $1=$ strongly disagree to $7=$ strongly agree).

Table 3. Statements included in the perceived accessibility scale (PAC).

\begin{tabular}{cl}
\hline PAC Item & Wording \\
\hline 1 & Considering how I travel today, it's easy to do (daily) activities. \\
2 & Considering how I travel today, I'm able to live my life as I want to. \\
3 & Considering how I travel today, I'm able to do all the activities I prefer to do. \\
4 & Considering how I travel today, access to my preferred activities is satisfying. \\
\hline
\end{tabular}

Travel satisfaction was measured using the satisfaction with travel scale (STS) [24,39]. The STS combines cognitive evaluations with measures of two orthogonal affect dimensions assumed to retrospectively assess mood or emotional wellbeing during travel. The measured dimensions (one cognitive and two affective) are distinct and positively correlated constructs included in a latent higher-order measure of overall satisfaction with travel. The items in the STS were answered on seven-point scales, ranging from negative (-3) to positive (3) (see Table 4). 
Table 4. Statements included in the satisfaction with travel scale (STS).

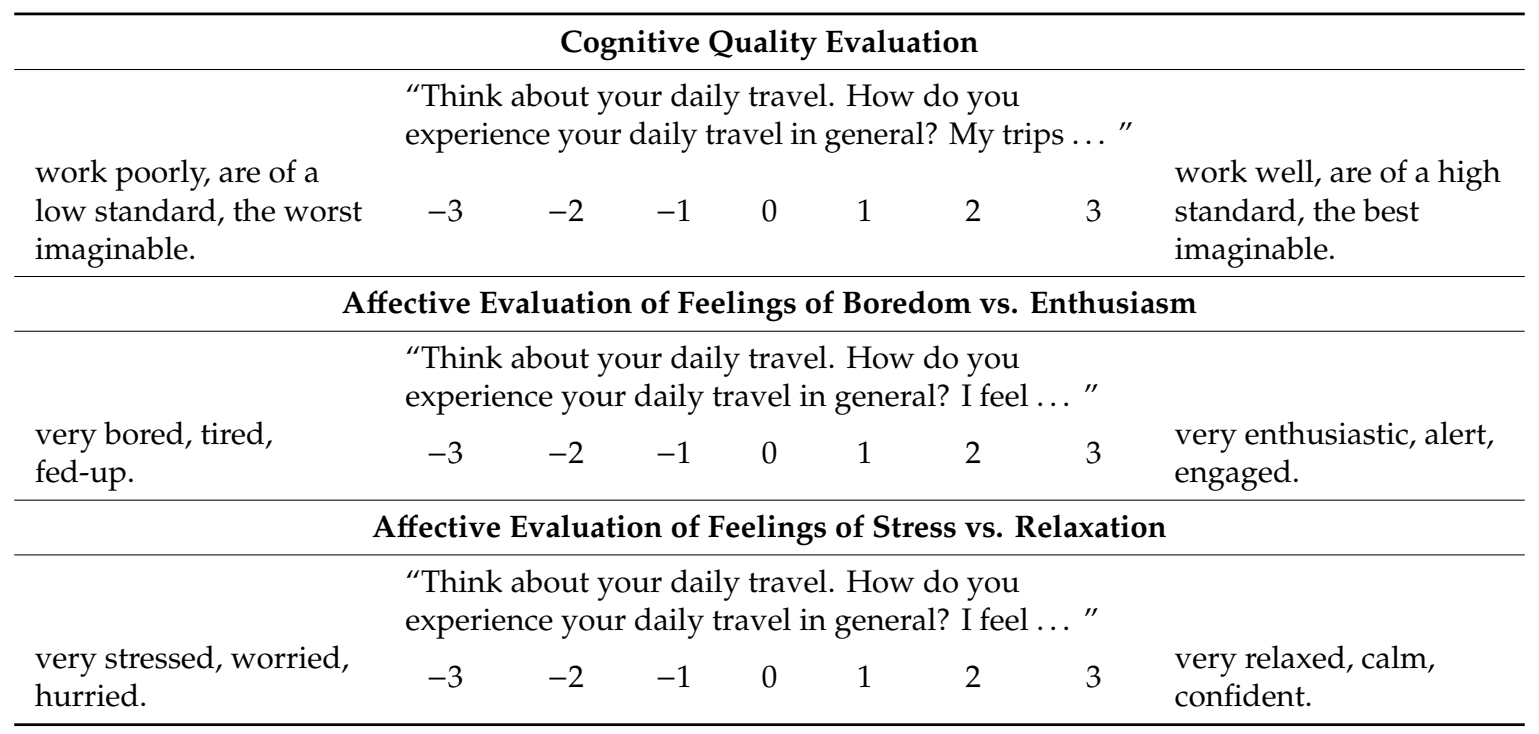

After the respondents had rated the perceived accessibility and satisfaction with travel scales, they were also asked about their life satisfaction (LS). Life satisfaction was measured using a single item: "Think about your daily life. All in all, how satisfied are you with your life on the whole?" and answered on a seven-point scale, ranging from (1) extremely dissatisfied to (7) extremely satisfied.

\subsection{Analyses}

The reported analysis is based on both analyses of variance (ANOVA) and partial least square structural equation modeling (PLS-SEM). The analyses were conducted in five steps: (1) testing mode use distribution between the different age groups by means of ANOVA, (2) testing the reliability and validity of the latent constructs, (3) testing the proposed model by means of PLS-SEM, (4) testing moderation by means of PLS multigroup analysis (PLS-MGA), and (5) testing the mean differences between the different age groups as regards perceived accessibility, travel satisfaction, and life satisfaction by means of ANOVA.

We applied a variance-based structural equation modeling technique of partial least squares (PLS-SEM). PLS-SEM was used because it relies on a nonparametric bootstrap procedure to test the path coefficients of the proposed model for their significance [40]. The analyses follow the recommended guidelines on how to report PLS-SEM [41].

\subsection{Ethical Statement}

This research does not fall under the Act on the Ethical Review of Research Involving Humans (Swedish Code of Statutes 2003:460), according to the local Research Ethics Committee at Karlstad University (dnr C2017/938). The research was conducted in accordance with approved research protocols. The procedure ensured that the participants were informed that their confidentiality would be maintained.

\section{Results}

\subsection{Travel Mode Use}

As shown in Table 5, mode use differs slightly between the age brackets, especially with respect to car and bike use, whereby those aged 75 and above (old and old with high longevity) report using their cars-both as drivers and passengers-and their bikes significantly less. For public transport use, no significant difference was observed; for walking, only very minor differences were found. In the 
table, the age group with the greatest use of each respective mode is marked in bold. As can be seen, those in early retirement seem to generally travel more frequently than the other age groups.

Table 5. Use of different modes (daily or a few times a week, in \%) and group comparisons between age groups, by Kruskal-Wallis ANOVAs.

\begin{tabular}{ccccccc}
\hline Mode & Pre-Retirement & $\begin{array}{c}\text { Early } \\
\text { Retirement }\end{array}$ & $\begin{array}{c}\text { Young } \\
\text { Old }\end{array}$ & Old & $\begin{array}{c}\text { Old with High } \\
\text { Longevity }\end{array}$ & $\begin{array}{c}\text { Group Comparisons } \\
\text { Using Kruskal-Wallis } \\
\text { ANOVAs (H) }\end{array}$ \\
\hline Car as driver & 55.5 & 56.5 & 55.0 & 47.5 & 36.1 & $\mathrm{H}=55.83, p<0.001$ \\
Car as passenger & 16.9 & 21.8 & 19.7 & 11.9 & 13.8 & $\mathrm{H}=27.11, p<0.001$ \\
Public transport & 34.9 & 36.6 & 31.4 & 33.3 & 36.2 & $\mathrm{H}=2.76, p=0.593$ \\
Bicycle & 22.6 & 24.0 & 20.8 & 15.3 & 12.3 & $\mathrm{H}=92.23, p<0.001$ \\
Walking & 30.5 & 35.5 & 32.2 & 27.5 & 29.2 & $\mathrm{H}=16.86, p=0.002$ \\
Other ${ }^{*}$ & 3.4 & 1.1 & 1.4 & 1.7 & 2.8 & \\
\hline & & &
\end{tabular}

\subsection{PLS-SEM}

To assess the appropriateness of the measurement model, and the latent constructs (PAC and STS), convergent validity, reliability, and discriminant validity were tested. These findings are presented below, followed by measures of model fit, explained variance, and predictive relevance. Next, the test of the structural model is reported on, and the significant direct paths are visualized (Figure 2), accompanied by detailed findings regarding all direct and indirect paths (Table 6).

\subsubsection{Reliability and Validity of the Latent Constructs}

The heterotrait-monotrait ratio of correlations (HTMT) was first assessed to confirm discriminant validity between the two latent variables. The findings were satisfactory, with the HTMT being above the suggested critical value of $<0.85$ [42]. Convergent validity was then evaluated using average variance extracted (AVE). AVE was above 0.50 [43], confirming a sufficient level of convergent validity. The reliability of the constructs was then assessed according to composite reliability (CR) and was found to exceed the recommended value of 0.708 [44] for both PAC and STS, providing strong support for construct reliability. In addition, the variance inflation factors (VIFs) were all below 5.0, indicating a lack of multi-collinearity between the constructs.

Predictive relevance, indicated by the Q2 measure, is a measure of how well PLS-SEM predicts the data points of the indicators. A value larger than zero indicates that the PLS path model has predictive relevance to a specific construct [40]. The Q2 value was found to exceed zero, for both STS and LS. The explained variance (R2adj) was $17 \%$ for STS and $14 \%$ for LS, and the model fit indices were acceptable $(\mathrm{SRMR}=0.03$, suggested critical value: $<0.08 ; \mathrm{rms}$ Theta $=0.15$, suggested critical value: $<0.12)$ [45] . Model fit indices should, however, be interpreted with caution in PLS-SEM as traditional and accepted threshold values may not be perfectly suited [40]. To sum up, the proposed model has acceptable validity, reliability, and predictive relevance.

\subsubsection{Testing the Structural Model}

Figure 2 shows the significant paths of the tested overall model. All direct effects related to STS and LS are reported in Table 6. As can be seen, a significant direct effect from PAC to STS ( $\beta=0.39$ ) was observed, showing that higher scores in PAC relate to higher STS. The same pattern was observed between STS and LS ( $\beta=0.13)$, and between PAC and LS ( $\beta=0.31)$, confirming the hypothesized positive relationship between travel satisfaction and life satisfaction, and between perceived accessibility and life satisfaction. Although somewhat weaker, a significant indirect effect of PAC on LS, through STS $(\beta=0.05)$, was also observed. 


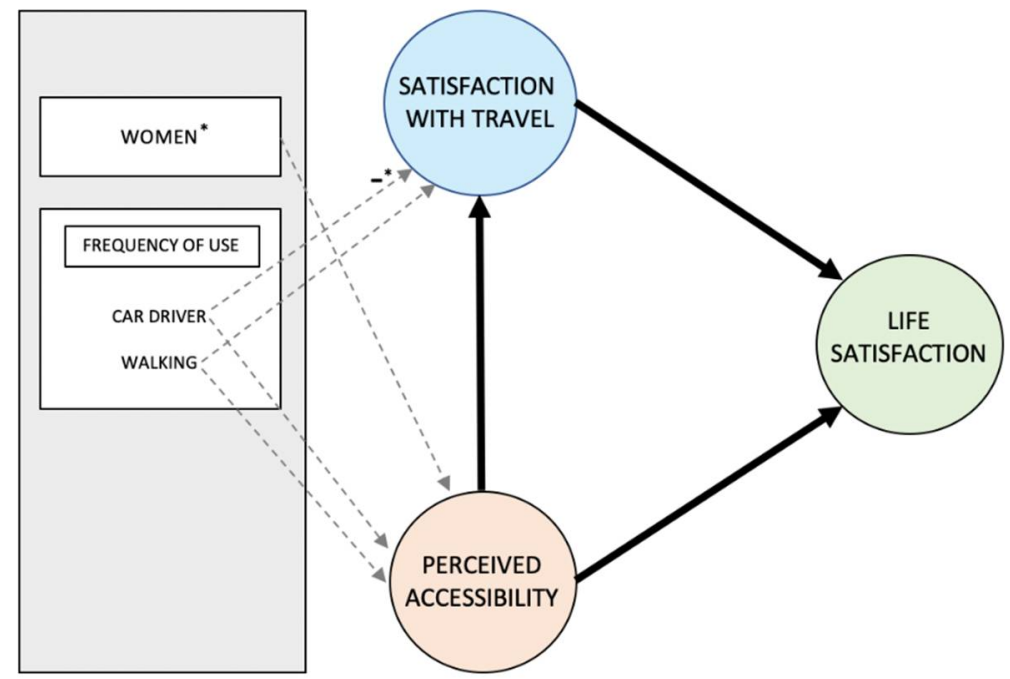

Figure 2. Significant $(p<0.05)$ direct effects on perceived accessibility, travel satisfaction and life satisfaction. Notes: The path between car driver and STS is marked with a minus sign, indicating a negative relationship. The remaining paths are positive. * indicate marginally significant path $[p<0.10]$.

A number of significant paths from mode use and gender to STS and PAC were observed. Using the car as a driver and walking more frequently are positive as regards PAC. Being female is related to higher perceived accessibility. For satisfaction with travel (STS), a positive path was observed as regards frequent walking, while driving more frequently was related to a lower STS.

Table 6. Direct effects reported in PLS-SEM of mode use, gender, perceived accessibility (PAC), satisfaction with travel (STS), and life satisfaction (LS).

\begin{tabular}{cccc}
\hline Direct Effects & $\boldsymbol{\beta}$ & $\mathbf{t}$ & $\boldsymbol{p}$ \\
\hline Bicycle $\rightarrow$ PAC & 0.032 & 1.630 & 0.103 \\
Bicycle $\rightarrow$ STS & 0.001 & 0.051 & 0.969 \\
Car as driver $\rightarrow$ PAC & 0.137 & 5.946 & $<0.001$ \\
Car as driver $\rightarrow$ STS & -0.039 & 1.843 & 0.065 \\
Car as passenger $\rightarrow$ PAC & -0.025 & 1.102 & 0.270 \\
Car as passenger $\rightarrow$ STS & -0.009 & 0.471 & 0.638 \\
PAC $\rightarrow$ LS & 0.307 & 11.751 & $<0.001$ \\
PAC $\rightarrow$ STS & 0.394 & 18.525 & $<0.001$ \\
Public transport $\rightarrow$ PAC & -0.021 & 0.913 & 0.361 \\
Public transport $\rightarrow$ STS & -0.026 & 1.167 & 0.243 \\
STS $\rightarrow$ LS & 0.132 & 5.612 & $<0.001$ \\
Walking $\rightarrow$ PAC & 0.074 & 3.254 & 0.001 \\
Walking $\rightarrow$ STS & 0.095 & 4.688 & $<0.001$ \\
Women $\rightarrow$ PAC & 0.040 & 1.808 & 0.071 \\
Women $\rightarrow$ STS & -0.024 & 1.203 & 0.229 \\
\hline
\end{tabular}

\subsubsection{Testing Moderation by Age Group}

Partial least square multigroup analysis (PLS-MGA) was performed to test the effects of moderation by age group on the structural model [40]. Four significant moderation effects were observed, displayed in Figure 3, with straight lines corresponding to the proposed moderation in the theoretical model, and dotted lines to the additional moderation observed in the empirical material. 


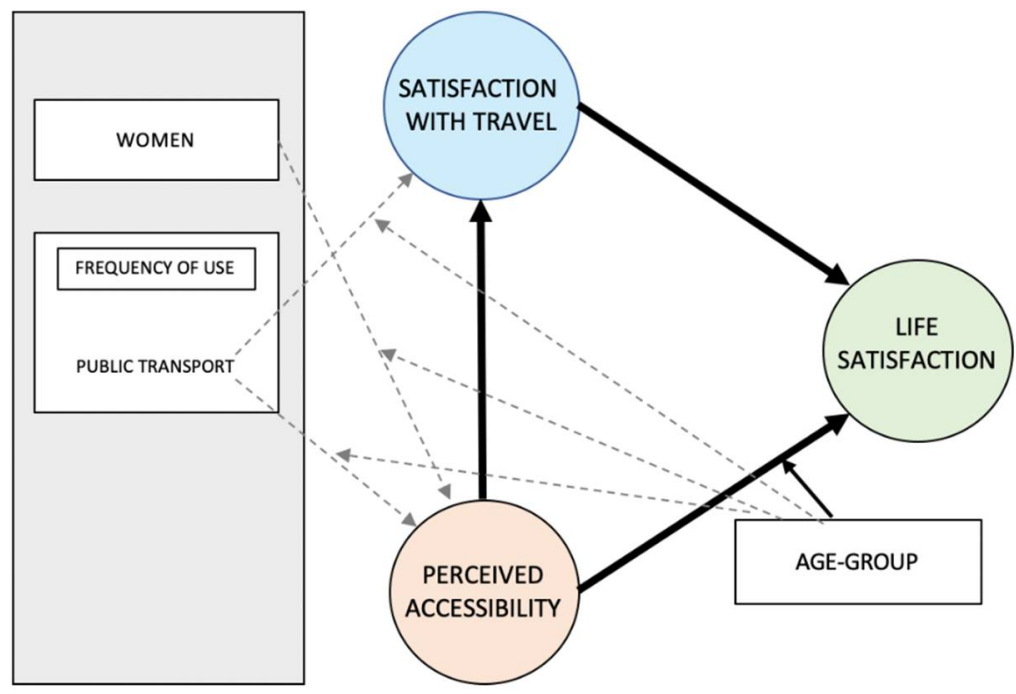

Figure 3. Significant $(p<0.05)$ moderating effects of age group.

In line with the theoretical model (Figure 1$)$, significant $(p<0.05)$ moderation by age group was observed in the relationships between PAC and LS. Specifically, weaker direct paths was observed for Pre-retirement $(p<0.05)$ and Early retirement $(p=0.055)$ as compared to the age group Old. However, significant moderation was though not, as hypothesized, observed for the paths between STS and PAC or STS and LS, indicating the importance of these relationships for all elderly.

Although not part of the theoretical model, three other significant moderation effects were observed in the empirical material: (i) The path between frequency of public transport use and PAC was negative in the two youngest age groups but positive in the three elderly age groups, indicating that more frequent public transport use relates to greater PAC in some (young old, old and old with high longevity) but the opposite in others (pre-retirement and early retirement). (ii) The path between frequency of public transport use and STS differed in strength for the age group Old as compared to the remaining age groups, where the Old yielded a significant positive relationship, whereas no significant path was observed for the remaining groups. (iii) Significant gender moderation was observed whereby being a female member of the oldest age group relates to a negative relationship with PAC, while positive relationships were observed in the other age groups.

\subsubsection{Comparisons of Means Across the Age Brackets for PAC, STS, and LS}

As a final analysis, comparisons of means (analyses of variance) regarding perceived accessibility, travel satisfaction, and life satisfaction were conducted across the age groups. The means and standard deviations across the age groups are displayed in Table 7. As can be seen, only small variations in means were found between the five age groups. Statistical analyses confirmed this since although showing significant differences $(p<0.05)$, effect sizes (Partial eta squared) were almost negligible, ranging from $0.004-0.008$.

Table 7. Means and standard deviations (in brackets) across the age groups for PAC, STS, and LS.

\begin{tabular}{cccccc}
\hline & \multicolumn{5}{c}{ Age Group } \\
\cline { 2 - 6 } Construct & Pre-Retirement & $\begin{array}{c}\text { Early } \\
\text { Retirement }\end{array}$ & $\begin{array}{c}\text { Young } \\
\text { Old }\end{array}$ & Old & $\begin{array}{c}\text { Old with High } \\
\text { Longevity }\end{array}$ \\
\hline Perceived Accessibility & $5.66(1.2)$ & $\mathbf{5 . 8 0}(1.2)$ & $5.78(1.2)$ & $5.71(1.3)$ & $5.56(1.3)$ \\
Satisfaction with Travel (1-7) & $5.01(1.1)$ & $5.20(1.1)$ & $\mathbf{5 . 2 7}(1.0)$ & $5.20(1.1)$ & $5.14(1.2)$ \\
Life Satisfaction (1-7) & $5.78(1.0)$ & $5.93(0.9)$ & $5.89(0.9)$ & $\mathbf{5 . 9 5}(0.9)$ & $5.94(0.9)$ \\
\hline
\end{tabular}

Note: The age group with the highest mean for each of the constructs is marked in bold. 


\section{Discussion}

The main question was if perceived accessibility is related to travel satisfaction and general life satisfaction of elderly and if there are differences regarding how they travel. As suggested by the theoretical model, perceived accessibility was found to be related to both satisfaction with travel and life satisfaction, while travel satisfaction was directly associated with life satisfaction. These findings show that the abilities of the elderly to participate in daily activities constitute an aspect that likely affects their overall life satisfaction, that subjective evaluations of travel are important to the elderly, and that both the possibility and ability to get around using the transport system relates to cognitive and emotional experiences while doing so.

Although these direct effects are important and interesting in themselves, it is also important to recognize that a proposed moderating effect of age group was confirmed, and especially so with respect to the old when compared with other groups. As Haustein et al. [46] point out, there is not much previous knowledge of the older groups of the elderly in research on daily travel, making this group appropriate to highlight in the following discussion. For this group, the path between perceived accessibility for life satisfaction is stronger in comparison to elderly people below the age of 75. Previous findings $[32,35]$ show that individuals start to engage more in in-home activities and less in out-of-home activities as their age increases. For the oldest, more and more activities may also be perceived as being too far away or too complicated to reach, leading to lower levels of perceived accessibility. Looking more closely at the travel behavior of all the groups, the oldest age groups stand out from the rest. They generally travel less than the other age groups and are, presumably, more reliant on the quality and overall experience of their travel due to issues of ageing and health. Although they travel by car and bicycle significantly less than the elderly aged up to 74, they still manage to walk and use public transport to much the same extent as other elderly people. Interestingly, the results show that frequent walking and car use are positively associated with perceived accessibility across all the age groups. For those in their 75-79, this general shift in travel and mode use may be perceived as dramatic and thus give raise to a stronger path to life satisfaction. In a few years' time, moving to the age bracket of 80 and above, it is likely that they have adapted to this new life situation and no longer have the same need to reach an array of daily activities as they previously did in life, making accessibility slightly less important again to overall life satisfaction. Other aspects of life more may have become more prominent for life satisfaction, e.g., health or family.

When the elderly travel, their travel needs to be of a good standard. In fact, in line with previous research on the links between satisfaction with travel and life satisfaction [25], our results show that satisfaction with travel is important in all age groups. Thus, even if perceived accessibility matters less for life satisfaction in some of the elderly groups, the quality and experiences of daily travel are always important.

Frequent public transport use is positive only for those over 70 and negative for those under 70 . This indicates that members of the elderly age groups travel to destinations using public transport that they perceive to be accessible, or that using public transport per se may be a social activity of choice, which affects their accessibility. Greater use of public transport before retirement, however, is associated with lower levels of accessibility. This may be due to the fact that the majority of the elderly in this group are still working $(<60 \%$, Table 2$)$, and that public transport may not be perceived to be accessible enough to meet the travel needs of these people.

Looking at the main effects of gender and perceived accessibility, it can be seen that women perceive their accessibility as higher than men do. This is in line with previous research on gender differences in perceived accessibility $[37,38]$. However, the moderation analysis shows that, for the oldest, women actually perceive their accessibility as lower than men do. Thus, the effect of gender partly contradicts previous findings. Unfortunately, we do not have an adequate explanation for this finding.

Bearing in mind that the groups in the present study are based on age (a five-year span), and not on life biographies, which are likely to extend across age segments, there is a possibility that the 
inclusion of other determinants in the models, e.g., health status, economic factors, relationship status, activities, or attitudes, would alter our findings somewhat. For instance, there is a possibility that, even though perceived accessibility and satisfaction with travel appear to be associated with life satisfaction, the effect of these relationships is marginal compared with other things in life, especially in the oldest groups. In the future, the inclusion of further variables in the models could help to better explain some of the differences between the age groups. For instance, the oldest groups may as well travel less for economic reasons, as for health issues, or be satisfied with traveling less due to the availability of social contacts nearby.

Finally, it is interesting to note that levels of perceived accessibility, satisfaction with travel, and life satisfaction do not differ between any of the age groups. This may indicate that, while there are differences in how these groups travel, e.g., frequency and mode use, they generally seem to be able to travel using modes that offer them acceptable levels of travel satisfaction and accessibility. However, this finding should be set in relation to previous studies which have come to the conclusion that levels of perceived accessibility decline with age $[37,47]$ and that subjective factors (e.g., attitudes) are better predictors of levels of perceived accessibility than sociodemographic factors are [37]. Moreover, individuals with mobility impairments caused by aging have been found to experience significantly lower levels of accessibility than other impairment groups [48]. As the majority of the elderly in all the age groups are still reliant on their private cars for daily travel (with $60 \%-70 \%$ using their cars as drivers or passengers either daily or a few times a week, in line with other findings from Northern Europe [49]), their levels of perceived accessibility will likely be affected if they are forced to use more sustainable modes. An enforced change from the car to sustainable travel modes was found, in a recent hypothetical study [50], to have a negative effect on perceived accessibility among frequent and less frequent car users. Given our findings, where frequent public transport use was negatively associated with perceived accessibility by the two youngest groups of elderly (a fraction of whom are still working), but positively associated by the old with high longevity, we recommend further research in order to obtain conclusive answers as regards how changes in transport mode use affect the different cohorts of the elderly.

\section{Conclusions}

This study offers original insights into the relationship between perceived accessibility, satisfaction with travel, and life satisfaction in different segments of the elderly. Through an empirical study of the travel behavior of elderly people of different ages, we show that perceived accessibility is significant to overall life satisfaction. For some of the elderly, this relationship is somewhat weaker; however, the concepts are still indirectly related via satisfaction with travel. We further show that satisfaction with travel is always important to older people's life satisfaction. We are thus able to conclude that the moderating role of age among the elderly clearly indicates that we should not always treat the elderly as one homogeneous group in transport planning. Based on our findings, we conclude that a continuous and long-term quality work is important with a special focus on segments of older groups in order to improve relevant and significant attributes. Grounded on previous research [31], we also recommend a special focus on safety, although additional knowledge is called for on the relationship between feeling safe, perceived service quality, and perceived accessibility. To gain a better understanding of the role of travel in old people's lives, we encourage future studies to include additional potential factors (e.g., attitudes and feelings of safety) of influence in the model.

Author Contributions: K.L., L.E.O., M.F. and S.F. conceived and designed the study; K.L., M.F. and L.E.O. analyzed the data and wrote the paper. All authors were involved and commented on the work during the pre-publication stages. The contribution from each author was substantial.

Funding: This research was financed by the Anne-Marie and Gustaf Ander Foundation (visiting professor's grant), and by the Swedish Energy Agency (Grant No. 46918-1). 
Conflicts of Interest: The authors declare that there are no conflict of interest. The founding sponsors played no part in designing the study, in collecting, analyzing, and interpreting the data, in writing the manuscript, or in deciding to publish the findings.

\section{References}

1. United Nations, Department of Economic and Social Affairs, Population Division. World Population Ageing 2015 (ST/ESA/SER. A/390); United Nations: New York, NY, USA, 2015.

2. Cohen, S.A.; Gössling, S. A darker side of hypermobility. Environ. Plan. A Econ. Space 2015, 47, 1661-1679. [CrossRef]

3. Larsen, J.; Axhausen, K.W.; Urry, J. Geographies of social networks: Meetings, travel and communications. Mobilities 2006, 1, 261-283. [CrossRef]

4. Preston, J.; Rajé, F. Accessibility, mobility and transport-related social exclusion. J. Transp. Geogr. 2007, 15, 151-160. [CrossRef]

5. Stanley, J.K.; Hensher, D.A.; Stanley, J.R.; Vella-Brodrick, D. Mobility, social exclusion and well-being: Exploring the links. Transp. Res. Part A Policy Pract. 2011, 45, 789-801. [CrossRef]

6. Lyubomirsky, S. The How of Happiness: A Scientific Approach to Getting the Life You Want; Penguin: New York, NY, USA, 2008.

7. Nordbakke, S. Mobilitet Blant Yngre, Eldre og Funksjonshemmede-bilens Rolle; Transportøkonomisk Institutt: Oslo, Norway, 2006.

8. European Road Safety Observatory. Older Drivers 2015; European Commission: Brussels, Belgium, 2015.

9. Siren, A.; Hakamies-Blomqvist, L. Private car as the grand equaliser? Demographic factors and mobility in Finnish men and women aged 65+. Transp. Res. Part F Traffic Psychol. Behav. 2004, 7, 107-118. [CrossRef]

10. Siren, A.; Haustein, S. Baby boomers' mobility patterns and preferences: What are the implications for future transport? Transp. Policy 2013, 29, 136-144. [CrossRef]

11. Su, F.; Bell, M.G. Travel differences by gender for older people in London. Res. Transp. Econ. 2012, 34, 35-38. [CrossRef]

12. Edwards, J.D.; Bart, E.; O'Connor, M.L.; Cissell, G. Ten years down the road: Predictors of driving cessation. Gerontologist 2009, 50, 393-399. [CrossRef] [PubMed]

13. Cui, J.; Loo, B.P.; Lin, D. Travel behaviour and mobility needs of older adults in an ageing and car-dependent society. Int. J. Urban Sci. 2017, 21, 109-128. [CrossRef]

14. Boschmann, E.E.; Brady, S.A. Travel behaviors, sustainable mobility, and transit-oriented developments: A travel counts analysis of older adults in the Denver, Colorado metropolitan area. J. Transp. Geogr. 2013, 33, 1-11. [CrossRef]

15. Hensher, D.A. Some insights into the key influences on trip-chaining activity and public transport use of seniors and the elderly. Int. J. Sustain. Transp. 2007, 1, 53-68. [CrossRef]

16. Giuliano, G.; Hu, H.H.; Lee, K. Travel Patterns of the Elderly: The Role of Land Use (No. FHWA/CA/OR-2003/06); METRANS Transportation Center: Los Angeles, CA, USA, 2003.

17. Currie, G.; Delbosc, A. Exploring public transport usage trends in an ageing population. Transportation 2010, 37, 151-164. [CrossRef]

18. Ryan, J.; Wretstrand, A.; Schmidt, S.M. Exploring public transport as an element of older persons' mobility: A Capability Approach perspective. J. Transp. Geogr. 2015, 48, 105-114. [CrossRef]

19. Hess, D.B. Walking to the bus: Perceived versus actual walking distance to bus stops for older adults. Transportation 2012, 39, 247-266. [CrossRef]

20. Cao, X.; Mokhtarian, P.L.; Handy, S.L. Neighborhood design and the accessibility of the elderly: An empirical analysis in Northern California. Int. J. Sustain. Transp. 2010, 4, 347-371. [CrossRef]

21. Pucher, J.; Buehler, R.; Merom, D.; Bauman, A. Walking and cycling in the United States, 2001-2009: Evidence from the National Household Travel Surveys. Am. J. Public Health 2011, 101, 310-317. [CrossRef]

22. Pucher, J.; Dijkstra, L. Promoting safe walking and cycling to improve public health: Lessons from the Netherlands and Germany. Am. J. Public Health 2003, 93, 1509-1516. [CrossRef]

23. Böcker, L.; van Amen, P.; Helbich, M. Elderly travel frequencies and transport mode choices in Greater Rotterdam, the Netherlands. Transportation 2017, 44, 831-852. [CrossRef] 
24. Friman, M.; Fujii, S.; Ettema, D.; Gärling, T.; Olsson, L.E. Psychometric analysis of the satisfaction with travel scale. Transp. Res. Part A Policy Pract. 2013, 48, 132-145. [CrossRef]

25. Ettema, D.; Gärling, T.; Olsson, L.E.; Friman, M. Out-of-Home Activities, Daily Travel, and Subjective Well-Being. Transp. Res. Part A Policy Pract. 2010, 44, 723-732. [CrossRef]

26. De Vos, J.; Schwanen, T.; Van Acker, V.; Witlox, F. Travel and subjective well-being: A focus on findings, methods and future research needs. Transp. Rev. 2013, 33, 421-442. [CrossRef]

27. Graham, H.; de Bell, S.; Flemming, K.; Sowden, A.; White, P.; Wright, K. Older people's experiences of everyday travel in the urban environment: A thematic synthesis of qualitative studies in the United Kingdom. Ageing Soc. 2018, 1-27. [CrossRef]

28. Gabriel, Z.; Bowling, A. Quality of life from the perspectives of older people. Ageing Soc. 2004, $24,675-691$. [CrossRef]

29. Musselwhite, C.; Haddad, H. Exploring older drivers perceptions of driving. Eur. J. Ageing 2010, 7, $181-188$. [CrossRef]

30. Ziegler, F.; Schwanen, T. 'I like to go out to be energised by different people': An exploratory analysis of mobility and wellbeing in later life. Ageing Soc. 2011, 31, 758-781. [CrossRef]

31. Lättman, K.; Friman, M.; Olsson, L.E. Perceived accessibility of public transport as a potential indicator of social inclusion. Soc. Incl. 2016, 4, 36-45. [CrossRef]

32. Banister, D.; Bowling, A. Quality of life for the elderly: The transport dimension. Transp. Policy 2004, 11, 105-115. [CrossRef]

33. Nordbakke, S.; Schwanen, T. Well-being and mobility: A theoretical framework and literature review focusing on older people. Mobilities 2014, 9, 104-129. [CrossRef]

34. Nordbakke, S.; Schwanen, T. Transport, unmet activity needs and wellbeing in later life: Exploring the links. Transportation 2015, 42, 1129-1151. [CrossRef]

35. Enam, A.; Konduri, K.C.; Eluru, N.; Ravulaparthy, S. Relationship between well-being and daily time use of elderly: Evidence from the disabilities and use of time survey. Transportation 2018, 45, 1783-1810. [CrossRef]

36. Ryan, J.; Wretstrand, A. What's mode got to do with it? Exploring the links between public transport and car access and opportunities for everyday activities among older people. Travel Behav. Soc. 2019, 14, 107-118. [CrossRef]

37. Van der Vlugt, A.L.; Curl, A.; Wittowsky, D. What about the people? Developing measures of perceived accessibility from case studies in Germany and the UK. Appl. Mobilities 2019, 1-21. [CrossRef]

38. Lättman, K.; Olsson, L.E.; Friman, M. A new approach to accessibility-Examining perceived accessibility in contrast to objectively measured accessibility in daily travel. Res. Transp. Econ. 2018, 69, 501-511. [CrossRef]

39. Ettema, D.; Gärling, T.; Eriksson, L.; Friman, M.; Olsson, L.E.; Fujii, S. Satisfaction with travel and subjective well-being: Development and test of a measurement tool. Transp. Res. Part F Traffic Psychol. Behav. 2011, 14, 167-175. [CrossRef]

40. Hair, J.F.; Sarstedt, M.; Ringle, C.M.; Gudergan, S.P. Advanced Issues in Partial Least Squares Structural Equation Modeling (PLS-SEM); Sage: Thousand Oaks, CA, USA, 2017.

41. Hair, J.F.; Risher, J.J.; Sarstedt, M.; Ringle, C.M. When to use and how to report the results of PLS-SEM. Eur. Bus. Rev. 2019, 31, 2-24. [CrossRef]

42. Henseler, J.; Ringle, C.M.; Sarstedt, M. A new criterion for assessing discriminant validity in variance-based structural equation modeling. J. Acad. Mark. Sci. 2015, 43, 115-135. [CrossRef]

43. Fornell, C.; Larcker, D.F. Evaluating structural equation models with unobservable variables and measurement error. J. Mark. Res. 1981, 18, 39-50. [CrossRef]

44. Hair, J.F.; Ringle, C.M.; Sarstedt, M. Partial least squares structural equation modeling: Rigorous applications, better results and higher acceptance. Long Range Plan. 2013, 46, 1-12. [CrossRef]

45. Henseler, J.; Hubona, G.; Ray, P.A. Using PLS path modeling in new technology research: Updated guidelines. Ind. Manag. Data Syst. 2016, 116, 2-20. [CrossRef]

46. Haustein, S.; Siren, A.K.; Framke, E.; Bell, D.; Pokriefke, E.; Alauzet, A.; Marin-Lamellet, C.; Armoogum, J.; O'Neill, D. Demographic Change and Transport; CONSOL Report; European Commission: Kongens Lyngby, DE, USA, 2013.

47. Schorr, A.V.; Iecovich, E.; Alfasi, N.; Shamai, S. Socio-Spatial Integration of Older Adults in Four Types of Residential Environments in Israel. J. Appl. Gerontol. 2017, 36, 1243-1271. [CrossRef] 
48. Marquez, L.; Poveda, J.C.; Vega, L.A. Factors affecting personal autonomy and perceived accessibility of people with mobility impairments in an urban transport choice context. J. Transp. Health 2019, 14, 100583. [CrossRef]

49. Luiu, C.; Tight, M.; Burrow, M. Factors preventing the use of alternative transport modes to the car in later life. Sustainability 2018, 10, 1982. [CrossRef]

50. Lättman, K.; Friman, M.; Olsson, L.E. Restricted car-use and perceived accessibility. Unpublished work.

(C) (1)

(C) 2019 by the authors. Licensee MDPI, Basel, Switzerland. This article is an open access article distributed under the terms and conditions of the Creative Commons Attribution (CC BY) license (http://creativecommons.org/licenses/by/4.0/). 